Abstract-We describe the lengthat-age relationship of cobia (Rachycentron canadum) with the use of 3 nonlinear models, and examine both the movement patterns of cobia in the Gulf of Mexico and South Atlantic Ocean and the instantaneous total mortality rate $(Z$, per year) from tag-recovery models with data from the Sport Fish Tag and Release Program of the University of Southern Mississippi Gulf Coast Research Laboratory. The estimated mean asymptotic length $\left(L_{\infty}\right)$ in this study (1172 $\mathrm{mm}$ in fork length [95\% confidence interval (CI): 1151-1192]) was in the range of values reported for this species in the Gulf of Mexico and Atlantic Ocean, and the annual growth coefficient ( $k: 0.57$ [95\% CI: $0.52-0.61]$ ) was greater than that reported for cobia elsewhere. Movements were reported between the Gulf of Mexico and the South Atlantic Ocean and a statistically significant seasonal trend in recaptures was observed, both of which suggest that cobia inhabit the Florida Keys during the winter and the northcentral Gulf of Mexico during the summer. The most supported tag-recovery model included time-invariant survivorship and time-dependent recovery probability and the estimated $Z$ was $0.59 /$ year (95\% CI: $0.55-0.63$ ). This study provides a summary of a long-term cobia tagging program and information for future management of this species.

Manuscript submitted 12 August 2016. Manuscript accepted 6 July 2017.

Fish. Bull. 115:460-472 (2017).

Online publication date: 1 August 2017. doi: 10.7755/FB.115.4.3

The views and opinions expressed or implied in this article are those of the author (or authors) and do not necessarily reflect the position of the National Marine Fisheries Service, NOAA.

\title{
Growth, mortality, and movement of cobia (Rachycentron canadum)
}

\author{
David A. Dippold (contact author) ${ }^{1}$ \\ Robert T. Leaf 1 \\ James S. Franks² \\ J. Read Hendon ${ }^{2}$
}

EEmail address for contact author: dippold.14@buckeyemail.osu.edu

1 Division of Coastal Sciences

The University of Southern Mississippi

703 East Beach Drive

Ocean Springs, Mississippi 39564

Present address for contact author: Department of Evolution, Ecology, and Organismal Biology The Ohio State University

1314 Kinnear Road

Columbus, Ohio 43212

2 Center for Fisheries Research and Development

Gulf Coast Research Laboratory

The University of Southern Mississippi

703 East Beach Drive

Ocean Springs, Mississippi 39564

The cobia (Rachycentron canadum) is a globally distributed, coastal pelagic species that supports both recreational and commercial fisheries in the Gulf of Mexico and U.S. Atlantic Ocean. Although cobia landings are primarily recreational ( $>80 \%$ of total annual landings 1990 to 2011; SE$\mathrm{DAR}^{1}$ ), cobia are also harvested commercially and caught incidentally as bycatch in shrimp fisheries. Cobia is currently managed and assessed as separate Gulf of Mexico and South Atlantic Ocean stocks, and harvest is regulated by an $84 \mathrm{~cm}$ (33 in) minimum fork length (FL) limit and a daily bag limit of 2 fish per angler. Since 2012, quotas have also been used to set annual harvest limits. Despite the historic and continued recreational and commercial harvest of cobia, very few assessments have

1 SEDAR (Southeast Data Assessment and Review). 2013. SEDAR 28-Gulf of Mexico cobia stock assessment report, 616 p. SEDAR, North Charleston, SC. [Available from website.] been conducted to determine the status of the Gulf of Mexico and South Atlantic Ocean stocks. The Gulf of Mexico stock was previously assessed in 1996 (Thompson ${ }^{2}$ ) by using virtual population analysis and in 2001 by using a surplus production model (Williams, 2001). The South Atlantic Ocean stock was previously assessed in 1994 and 1995 by using virtual population analysis (Thompson ${ }^{3,4}$ ).

2 Thompson, N. B. 1996. An assessment of cobia in southeast U.S. waters. Natl. Mar. Fish. Serv., Southeast Fish. Sci. Cent., Miami Lab. Contrib. No. MIA95/96-28, 16 p. [Available from website.]

3 Thompson, N. B. 1994. An assessment of cobia in southeast U.S. waters. Natl. Mar. Fish. Serv., Southeast Fish. Sci. Cent., Miami Lab. Contrib. No. MIA93/94-38, 17 p. [Available from website.]

4 Thompson, N. B. 1995. An assessment of cobia in southeast U.S. waters. Natl. Mar. Fish. Serv., Southeast Fish. Sci. Cent., Miami Lab. Contrib. No. MIA-94/95-31, 25 p. [Available from website.] 
The species has only recently been assessed under the Southeast Data, Assessment, and Review (SEDAR) process (SEDAR ${ }^{1}$ ) and the most recent SEDAR assessment involved a separate assessment of the Gulf of Mexico and South Atlantic Ocean stocks.

In the most recent SEDAR assessments, several information gaps were identified which limited the determination of the status of both the Gulf of Mexico and South Atlantic Ocean cobia stocks. Specifically, there was an insufficient amount of information available to accurately determine stock boundaries, and further descriptions of life-history characteristics and population dynamics were needed. Towards this end, we used information from the Sport Fish Tag and Release Program of the University of Southern Mississippi Gulf Coast Research Laboratory (Hendon and Franks ${ }^{5}$ ) to investigate the growth, movement, and mortality of cobia in the Gulf of Mexico and South Atlantic Ocean in order to fill critical information gaps regarding lifehistory and population dynamics for this species, as well as to corroborate existing life-history descriptions by using an alternative source of information. We focus on the stocks of the Gulf of Mexico and South Atlantic Ocean, given that stocks of these areas were the focus of a cooperative tagging program.

Cooperative tagging programs can provide valuable information at the individual and population levels and on the fishery dynamics of recreationally and commercially harvested species (Wood and Cadrin, 2013). Cooperative tagging programs have been implemented for several groups of marine fishes, such as dolphinfish, sailfish, marlin, and sharks, and information from these programs has provided invaluable and previously unreported information on the movement and biology of these taxa (Jones and Prince, 1998; Kohler et al., 1998; Ortiz et al., 2003). For example, cooperative tagging programs have been used to estimate mortality (Pine et al., 2003; Wood and Cadrin, 2013), describe individual growth dynamics (Simpfendorfer, 2000; Dippold et al., 2016), and show movement patterns (Hendon et al., 2002; Queiroz et al., 2005; Hussey et al., 2009). In this study we used similar methods with a 27-year cooperative tagging data set (Hendon and Franks ${ }^{5}$ ). Although other cobia tagging programs exist in the Gulf of Mexico and South Atlantic Ocean (Shaffer and Nakamura, 1989; Burns and Neidig6; Wiggers ${ }^{7}$; Orbesen ${ }^{8}$ ), to our knowledge

\footnotetext{
${ }^{5}$ Hendon, J. R. and J. S. Franks. 2010. Sport fish tag and release in Mississippi coastal waters and the adjacent Gulf of Mexico. Gulf Coast Res. Lab. Tech. Rep. F-132, 34 p. [Available from Gulf Coast Research Laboratory, 703 East Beach Dr., Ocean Springs, MS 39564.]

${ }^{6}$ Burns, K. M., and C. L. Neidig. 1992. Cobia (Rachycentron canadum) amberjack (Seriola drumerili) and dolphin (Corypheana hippurus) migration and life history study off the southwest coast of Florida. Mote Mar. Lab. Tech. Rep. 267, 58 p. [Available from website.]

${ }^{7}$ Wiggers, R. K. 2010. South Carolina marine game fish tagging program 1978-2009. South Carolina Dep. Nat. Resour., Charleston, SC. [Available from website.]

8 Orbesen, E. 2012. Constituent based tagging of cobia in
}

the Sport Fish Tag and Release Program is the most comprehensive.

Individual growth has previously been described in cobia by using otolith- and scale- derived age estimates, and annuli formation has been validated by using marginal increment analysis (Richards, 1967; Thompson et al. ${ }^{9}$; Smith, 1995; Franks et al., 1999). However, the use of marginal increment analysis as a method for age validation can be problematic because of the difficulty in interpreting the otolith margin and because of the need to validate annuli formation across the entire lifespan of a species (Campana, 2001). Age corroboration, or the estimation of growth parameters with alternative methods, is used to increase confidence in growth model parameter estimates (Campana, 2001). Specifically, tag-recapture information for estimating growth parameters has been used as an alternative method for describing the length-at-age relationship in several marine species (Natanson et al., 1999; Dippold et al., 2016). No age corroboration method has been evaluated for cobia, and because cobia are assessed by using a statistical catch-at-age model (SEDAR ${ }^{1}$ ), accurate descriptions of length-at-age are needed to estimate age-specific vital rates such as instantaneous fishing-induced [also termed "fishing mortality] and natural mortality. In this study, we use a suite of nonlinear length-at-age models to analyze tag-recapture data in order to corroborate existing estimates of the length-at-age relationship of cobia.

In addition to describing the length-at-age relationship, information from tagging programs can be used to describe general and seasonal movement and distribution patterns and to determine stock boundaries (Wood and Cadrin, 2013; Kneebone et al., 2014). The results of small-scale cooperative tagging of cobia have suggested that some individuals migrate long distances and indicate seasonal movement patterns (Shaffer and Nakamura, 1989; Burns and Neidig6; Wiggers ${ }^{7}$; Orbesen $\left.^{8}\right)$. However, in these studies, either relatively few individuals were tagged, only a small portion of tagged individuals was recaptured, the study occurred over a small sampling period, or long-distance movement was reported for only a few individuals. The determination of cobia stock boundaries is critical given the reported movements of this species between ocean basins. Genetic analysis to determine cobia stock discrimination has been evaluated for the Atlantic Ocean but has not been evaluated for the Gulf of Mexico (Darden et al., 2014). Because of the lack of resolution regarding seasonal movement patterns and the degree of mixing between the Gulf of Mexico and Atlantic Ocean cobia populations from both tagging and genetic studies, the current stock boundary between the Gulf of Mexico and

the Atlantic and Gulf of Mexico waters. Southeast Data Assessment and Review SEDAR28-DW13, 10 p. [Available from website.]

9 Thompson, B. A., C. A. Wilson, J. H. Render, and M. Beasley. 1992. Age, growth, and reproductive biology of greater amberjack and cobia from Louisiana waters, 55 p. Louisiana State University, Baton Rouge, LA. 
Atlantic Ocean cobia stocks needs to be more accurately defined (SEDAR ${ }^{1}$ ) to aid future assessments.

Estimates of mortality from tagging programs can improve stock assessment efforts by providing an alternative estimate of natural, fishing, or total mortality independent of the stock assessment model (Wood and Cadrin, 2013; Kerns et al., 2015). Several types of tag-recapture methods exist (Pine et al., 2003), and for cooperative tagging programs, tag-recovery models are used to estimate survivorship and the probability of tag recovery (Brownie et al., 1985). Tag-recovery methods for estimating mortality have been used for yellowtail flounder (Limanda ferruginea) in New England (Wood and Cadrin, 2013), walleye (Sander vitreus) in Lake Erie (Vandergoot and Brenden, 2014) and paddlefish (Polyodon spathula) in a South Dakota lake (Pierce et al., 2015). Estimates of mortality derived from tagrecapture data can be used to corroborate estimates derived with age-structured models or life-history-based approaches (Then et al., 2015).

The goals for this study were to use data from a 27-year cooperative tagging program to describe the growth, mortality, and movement of cobia in the Gulf of Mexico and South Atlantic Ocean. Specifically, we 1) describe the length-at-age relationship of cobia using a suite of nonlinear length-at-age models fitted to the tag-recapture data, 2) report cobia movement between the Gulf of Mexico and South Atlantic Ocean, 3) describe the spatial and seasonal distribution of cobia in the Gulf of Mexico, and 4) estimate annual instantaneous total mortality $(Z)$, using a suite of tag-recovery models. The results of this study will help fill existing information gaps and provide critical information to support the sustainable management of cobia in the Gulf of Mexico and South Atlantic Ocean.

\section{Materials and methods}

\section{Tagging and recapture}

The Sport Fish Tag and Release Program (Hendon and Franks ${ }^{5}$ ) began in 1988 as a cooperative tagging program during which volunteer recreational anglers tagged cobia with 10 -cm plastic-tipped dart tags (Hallprint Pty. Ltd. ${ }^{10}$, Hindmarsh Valley, Australia). Anglers participating in the program received tagging kits containing tags with unique numerical identifiers, data reporting cards, a tag applicator, and a booklet containing tagging instructions. Tagging guidelines provided with the tagging kit instructed anglers on the proper tag-release procedures to enhance tag retention and ensure safe handling of tagged fish before release. At the time of tagging, volunteer anglers recorded information on the approximate tagging location, date, the length of the fish (typically measured

\footnotetext{
${ }^{10}$ Mention of trade names or commercial companies is for identification purposes only and does not imply endorsement by the National Marine Fisheries Service, NOAA.
}

as FL in inches), and a qualitative description of fish condition at time of release. Anglers then mailed the tag-reporting card to the Gulf Coast Research Laboratory where the tagging data were recorded and entered into an electronic tag-recapture database. If a fish was recaptured, anglers were asked to report their catch by email, mail, or phone to the Gulf Coast Research Laboratory and provide information on the date of capture, location of catch, length-at-recapture, and whether the fish was retained or released, and if released, to provide a qualitative report on its condition.

The cooperative tagging program was advertised broadly and frequently. Posters describing the program were distributed to bait and tackle shops, boat launches, fishing tournaments, and sporting goods stores. The program was also occasionally reported in the media through newspaper articles, local television interviews, and regional fishing magazines. No financial incentives were offered during the program duration, but anglers who tagged numerous cobia in a given year were given informal recognition in the media and regional fishing magazines. Often, anglers who recaptured a tagged cobia became interested in obtaining a cobia tagging kit.

\section{Growth}

To describe the length-at-age relationship, 3 nonlinear length-at-age models were fitted to the cobia tag-recapture informatiion. Multimodel approaches for describing growth can help reduce model misspecification and can help identify the most appropriate length-at-age model to use for a particular species (Katsanevakis, 2006). Each of the 3 models used were reparameterized versions of commonly used length-at-age models, reformulated to fit the observed change in length information over the time that tagged fish were at large. Before model fittings, if a length-at-tagging or recapture was reported as total length (TL), it was converted to FL by using a TL-to-FL linear model conversion. The first model used was the Fabens (1965) von Bertalanffy growth function (VBGF). The Fabens model is

$$
\Delta L=\left(L_{\infty}-L_{\mathrm{t}}\right)\left(1-e^{-\mathrm{k} \Delta \mathrm{t}}\right),
$$

where $L_{\infty}=$ the mean asymptotic length (millimeters in FL); and

$k=$ the growth coefficient (per year).

The observed data used in the model are $\Delta L$, the change in length (millimeters in FL), and $\Delta t$, the time between tagging and recapture events (in years).

The second model used to describe the length-at-age relationship of cobia was a reparameterized Gompertz model (Troynikov et al., 1998):

$$
\Delta L=L_{\infty}\left(\frac{L_{\mathrm{i}}}{L_{\infty}}\right)^{\exp (-\mathrm{k} \Delta \mathrm{t})}-L_{\mathrm{i}},
$$

where $L_{\infty}=$ again the mean asymptotic FL (millimeters in FL); and

$k=$ the decrease in growth increment (per year) as length increases.

The observed data used in the model are $\Delta t$ (years), the 
time between tagging and recapture, and $L_{\mathrm{i}}$ the length at tagging (millimeters in FL).

The final model used to describe the length-at-age relationship of cobia was the VBGF formulation GROTAG, which is based on the methods discussed in Francis (1988). The Francis (1988) equation is

$$
\Delta L=\left(\frac{\beta g_{\alpha}-\alpha g_{\beta}}{g_{\alpha}-g_{\beta}}-L_{1}\right)\left(1-\left(1+\frac{g_{\alpha}-g_{\beta}}{\alpha-\beta}\right)^{\Delta \mathrm{t}}\right),
$$

where $\Delta L=$ the expected change in length (millimeters in $\mathrm{FL}$ );

$\Delta t=$ the time-at-large (years);

$L_{1}=$ the length of an individual at tagging (millimeters in FL); and

$g_{\alpha}$ and $g_{\beta}=$ the mean annual growth rates (millimeters per year) of fish at user-selected lengths $\alpha$ and $\beta$ (millimeters in FL).

The lengths $\alpha$ and $\beta$ are chosen based on the range of lengths included in the tag-recapture records so that $g_{\alpha}$ and $g_{\beta}$ are descriptive of the individual growth rates encompassed by the tagging data (Francis, 1988). In this study $\alpha$ was $500 \mathrm{~mm}$ FL and $\beta$ was $1100 \mathrm{~mm}$ FL. After fitting the model, $L_{\infty}$ (millimters in FL) can be estimated from $g_{\alpha}$ and $g_{\beta}$ with the following equation:

$$
L_{\infty}=\left(\beta g_{\alpha}-\alpha g_{\beta}\right)\left(g_{\alpha}-g_{\beta}\right) .
$$

Similarly, $k$ (per year) can be calculated from the GROTAG VBGF model parameters by using the following equation:

$$
k=-\ln \left(1+\left(g_{\alpha}-g_{\beta}\right) /(\alpha-\beta)\right.
$$

The $95 \%$ confidence intervals (CIs) of $L_{\infty}$ and $k$ were determined by using bootstrap methods similar to those described in Simpfendorfer (2000).

After each model was fitted, the performance of the 3 candidate models was compared by using Akaike's information criterion (AIC) (Burnham and Anderson, 2002) and model support was evaluated by using Akaike weights $\left(w_{\mathrm{i}}\right)$. The mean growth-parameter estimates of the best supported model(s) were compared with those reported in other studies of cobia growth published in the literature. All analyses were conducted in $R$, vers. 3.3.0 ( $R$ Core Team, 2016).

\section{Movement and seasonal distribution}

Broad-scale seasonal and general movements were described in this study by defining 7 spatial zones and quantifying the spatial and temporal patterns of fish tagged and recaptured among the zones. The criteria we used to define the 7 spatial zones were based on areas where recreational fishermen are known to target cobia and where boundaries exist that could be useful to managers when setting harvest regulations (e.g., state boundaries). Zones were also identified because exact locations of capture or recapture are generally not reported. In this study, the 7 geographic zones defined were Texas, Louisiana, northcentral Gulf of Mexico, Florida panhandle, Florida Gulf Coast, Flori- da Keys, and the U.S. South Atlantic Ocean (Fig. 1). We focused on the Gulf of Mexico and South Atlantic Ocean because those were the areas in which the cooperative tagging program occurred. Movement among zones was described by calculating the proportion of recaptured individuals in each zone that were tagged in a specific zone. We included only individuals whose time at liberty was greater than or equal to 30 days. Our analysis was used to investigate large-scale movement between geographic areas and to identify whether individual cobia traveled between the Gulf of Mexico and South Atlantic Ocean.

The relationship between recapture zone and month of recapture was evaluated by using a loglinear model to infer trends in seasonal distribution of recaptured cobia in the Gulf of Mexico. Recaptures from the South Atlantic Ocean were not included in the analysis to meet assumptions in the model regarding nonzero expected frequencies within each month-zone combination and because of the limited number of reported recaptures in the South Atlantic Ocean. We set a minimum time-at-liberty of 30 days to allow for tagged fish to return to normal mixing behavior. Loglinear models are an extension of the chi-square test and are used to determine associations between categorical variables (Knoke and Burke, 1980). A saturated loglinear model (with recapture zone and recapture month as the main effects) and a 2-way interaction term were constructed to evaluate the association between month of recapture and recapture zone. The saturated model is

$$
\log \left(u_{\mathrm{ij}}\right)=\lambda^{\text {zone }}+\lambda^{\text {month }}+\lambda^{\text {zone } \times \text { month }},
$$

where $\log \left(u_{\mathrm{ij}}\right)=$ the expected counts in each zone-month combination; and

$\lambda=$ the main effect of each predictor variable.

If no significant interaction is observed in the saturated model (indicating a good model fit), the interaction term is dropped and a second model with only the main effects is constructed. If this model is significant, i.e., the model does not fit the data well after removing the interaction term, the association between the main effects is considered significant (i.e., the model fits better when there is an association between the main effects). Finally, a mosaic plot was constructed that was based on the loglinear model to identify specific recapture zone and recapture month combinations that were statistically significant. Mosaic plots are useful visual representations that allow determination of statistically significant month-zone groups. Typically, the shading of mosaic plots represents the residuals (deviations) from the loglinear model for each cell. In this study, the shading of the mosaic plot represents the values of the Pearson (standardized) residuals and a value greater than 2 or less than -2 is considered significant.

\section{Mortality}

Estimates of $Z$ were determined by using a suite of tag-recovery models fitted to the cobia tagging data in 


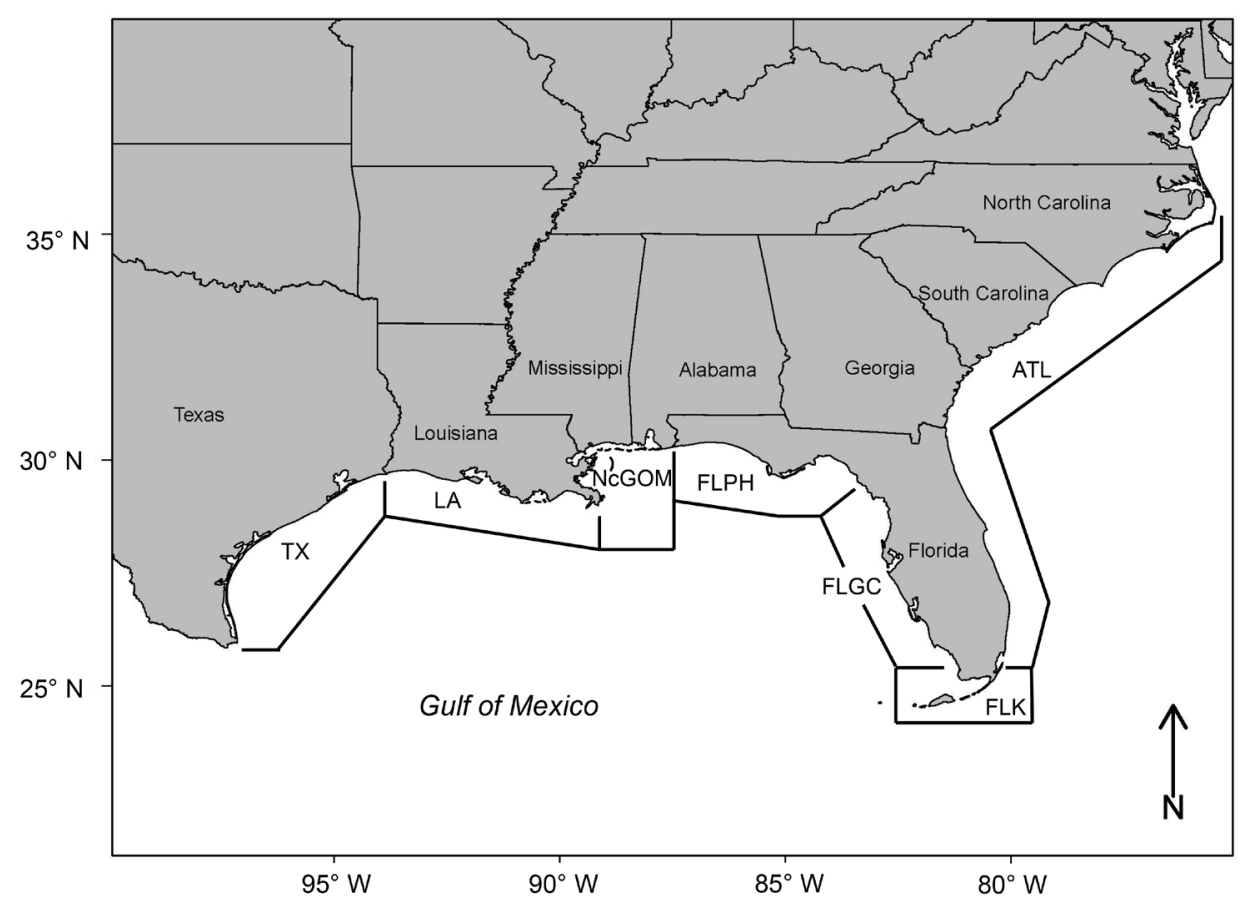

Figure 1

Map of the 7 geographic zones used to determine large-scale and seasonal movements of cobia (Rachycentron canadum) tagged and recaptured in the Gulf of Mexico and South Atlantic Ocean during 1988-2014. The 7 zones are Texas (TX), Louisiana (LA), northcentral Gulf of Mexico (NcGOM), Florida panhandle (FLPH), Florida Gulf Coast (FLGC), Florida Keys (FLK), and the South Atlantic Ocean (ATL).

Program MARK, vers 7.2 (Brownie et al., 1985; White and Burnam, 1999). The tag-recovery model is based on the probability that a tagged individual will experience one of the following 3 events: it will survive to the next year; be harvested by an angler and reported; or it will die of natural causes or be harvested and not reported (Fig. 2). In this analysis, maximum likelihood was used to estimate 2 parameters in the tag-recovery model: survivorship to the next year $(S)$ and the probability of tag recovery $(f)$. The $f$ parameter is the joint probability that a tagged cobia will be recaptured, harvested, and reported. In all candidate models, an annual time-step was used ( $n=27$ years). We assume that all tagged individuals had an equal probability of being recaptured, and that tagging occurs instantaneously during the designated time interval. The suite of models we evaluated included all combinations of time-dependent $(t)$ and time-independent (.) survi-

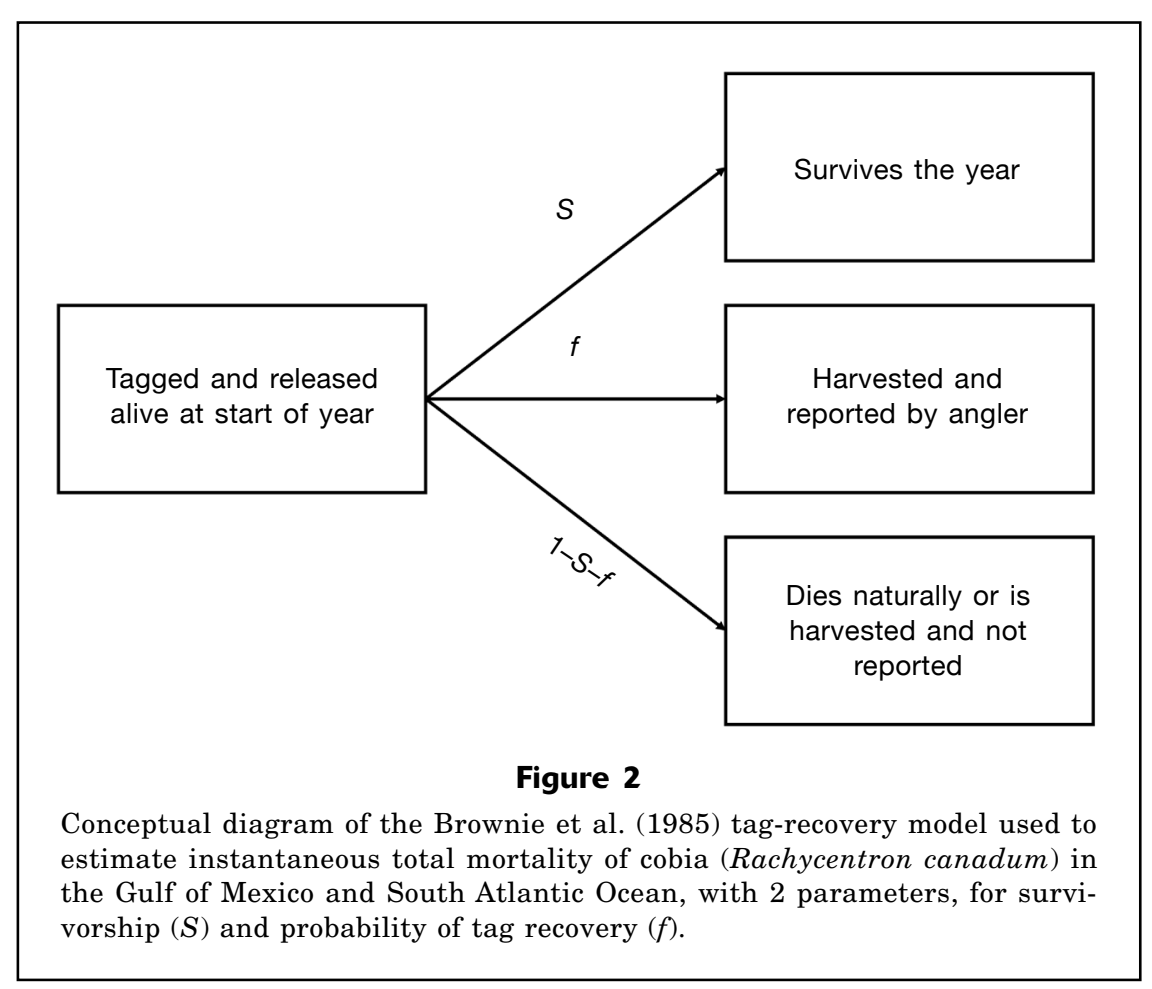



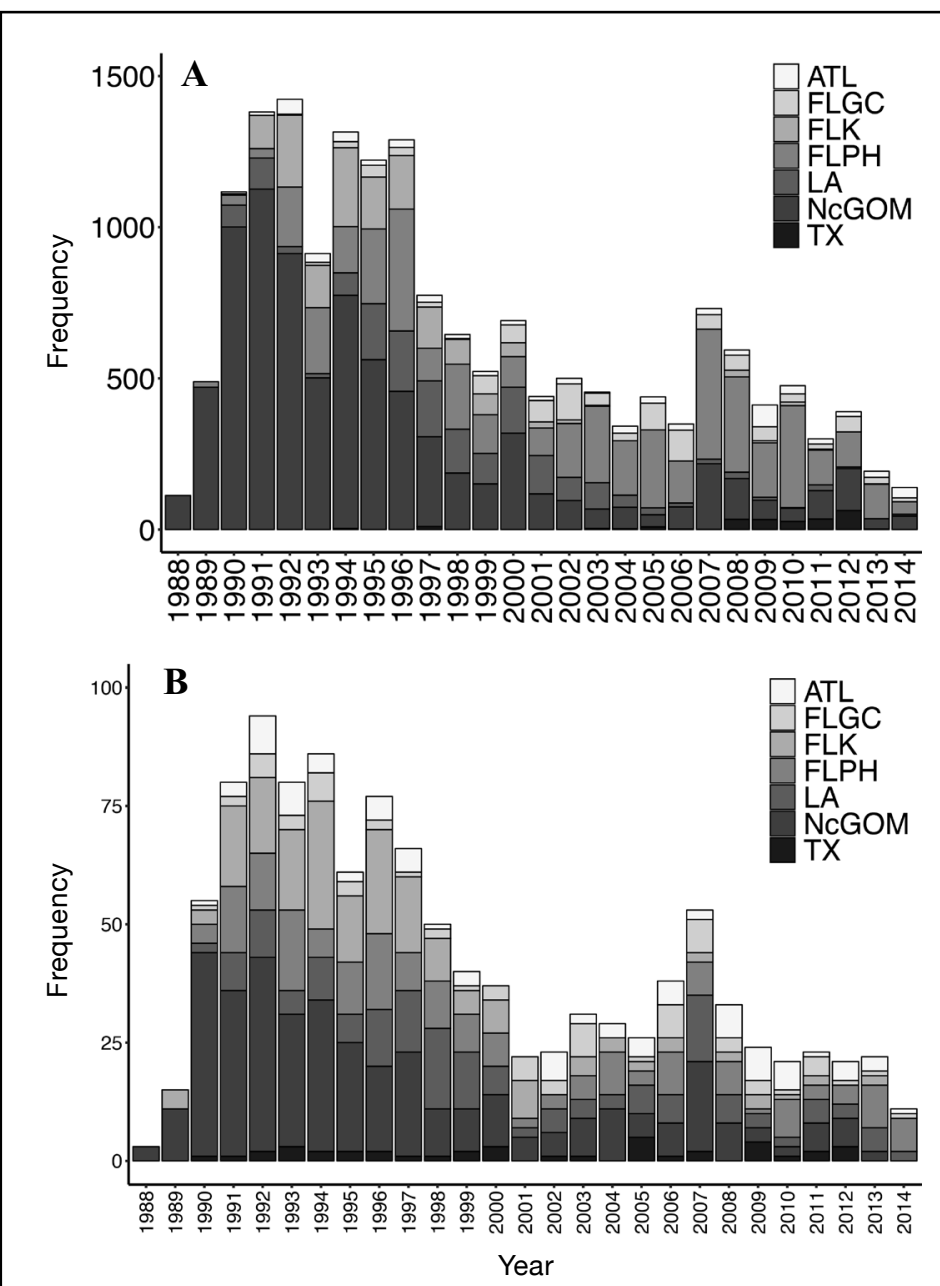

Figure 3

Total number of cobia (Rachycentron canadum) (A) tagged and (B) recaptured by year in each of 7 geographic zones in the Gulf of Mexico and South Atlantic Ocean during 1988-2014. The 7 defined zones are the South Atlantic Ocean (ATL),Florida Gulf Coast (FLGC), Florida Keys (FLK), Florida panhandle (FLPH), Louisiana (LA), northcentral Gulf of Mexico (NcGOM), and Texas (TX).

vorship and tag-recovery (4 candidate models). Timedependent parameters were those that varied by year and time-independent parameters were those that were constant through the duration of the tagging program. The global model (fully parameterized) was defined as having time-dependent survivorship, $S(t)$, and time-dependent tag-recovery, $f(t)$. Global model fit was evaluated by using the constant noted as $\hat{c}$, which is an estimate of dispersion used in Program MARK. To estimate dispersion, a simulation procedure is used in which data are generated at varying levels of $\hat{c}$ and a logistic model is then fitted to estimate $\hat{c}$ for the global model. A $\hat{c}$ value of less than 3.0 indicates adequate model fit. After the suite of candidate models were fitted to the tag-recapture data and the global model was determined to adequately fit the data, model support was evaluated by using AIC (Burnham and Anderson, 2002). The model with the greatest support (lowest AIC value) was used to estimate mean annual $Z$. The estimates of $Z$ derived in this study were then compared with the mortality values reported in both the Gulf of Mexico and South Atlantic Ocean cobia stock assessments (SEDAR ${ }^{1}$ ) by converting the value of $S$ estimated in this study to an estimate of $Z$ with the equation

$$
S=e^{-Z} \text {. }
$$

\section{Results}

\section{Tagging program}

A total of 17,875 cobia were tagged from 1988 to 2014. The number of individuals tagged annually ranged from 113 to 1423 individuals. A majority (57\%) of tagging occurred between 1990 and 1998 (Fig. 3). The reported length of tagged individuals ranged from $178 \mathrm{~mm}$ to $1549 \mathrm{~mm}$ FL (Fig. 4A). A total of 1137 individuals were recaptured, and the number of recaptured individuals annually varied from 3 to 94 individuals. The annual number of individuals recaptured was greatest from 1990 to 1998 (Fig. 3). The reported length of recaptured individuals ranged from 305 to $1448 \mathrm{~mm}$ FL (Fig. 4B), and the time between tagging and recapture ranged from 1 to 2973 days at large (Fig. 4C). Of the 7 zones defined in this study, the northcentral Gulf of Mexico zone had the greatest number of tagged and recaptured individuals and the Texas zone had the fewest number of tagged and recaptured individuals (Table 1 ).

\section{Growth}

Only individuals for which lengths at tagging and recapture were recorded were used in the growth analysis $(n=926)$. All reported lengths were converted to FL using the linear relationship between TLs and FLs $(F L=0.91 T L+0.23$; coefficient of determination $\left[r^{2}\right]=0.98$ ) developed from lengths reported in this study. Sex of tagged and recaptured individuals was not reported in this cooperative tagging program and therefore we modeled sex-combined length-at-age. The 3 nonlinear length-at-models were fitted, and the relative model support was evaluated with AIC (Table 2 ). Of the 3 candidate models, the GROTAG VBGF was best supported on the basis of calculated values of $w_{\mathrm{i}}$ $(\sim 1.0)$. However, on the basis of the mean and $95 \%$ CIs of the $L_{\infty}$ parameter, there was no difference in the mean estimates of $L_{\infty}$ among the 3 candidate models. The mean value of $k$ did vary (on the basis of $95 \%$ CIs) for each of the 3 candidate models. Specifically, the mean value of $k$ estimated in the GROTAG VBGF 

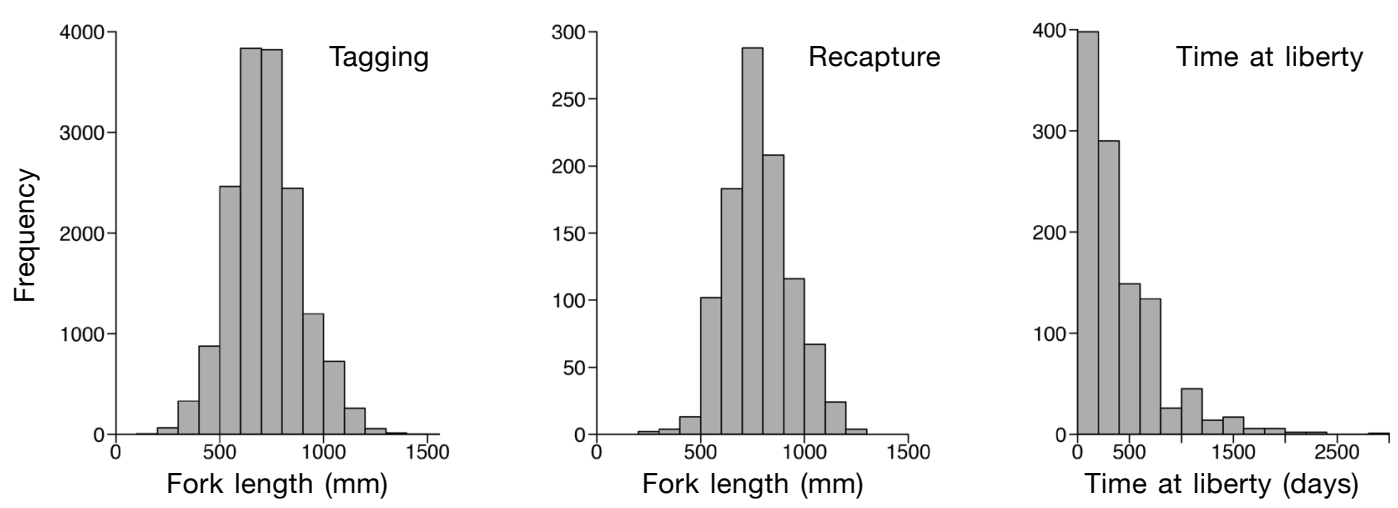

Figure 4

Histograms of length frequency for cobia (Rachycentron canadum) at tagging, and recapture , and time at liberty from time of tagging to time of recapture in the Gulf of Mexico and South Atlantic Ocean during 1988-2014.

\begin{tabular}{|c|c|c|}
\hline \multicolumn{3}{|c|}{ Table 1} \\
\hline \multicolumn{3}{|c|}{$\begin{array}{l}\text { Total number of cobia (Rachycentron canadum) tagged } \\
\text { and recaptured during 1988-2014 in each of } 7 \text { geo- } \\
\text { graphic zones in the Gulf of Mexico and South Atlantic } \\
\text { Ocean. The } 7 \text { zones are South Atlantic Ocean (ATL), } \\
\text { Florida Gulf Coast (FLGC), Florida Keys (FLK), Florida } \\
\text { panhandle (FLPH), Louisiana (LA), northcentral Gulf of } \\
\text { Mexico (NcGOM), and Texas (TX). }\end{array}$} \\
\hline Zone & Tagged & Recaptured \\
\hline ATL & 557 & 90 \\
\hline FLGC & 961 & 73 \\
\hline FLK & 1518 & 189 \\
\hline FLPH & 4620 & 190 \\
\hline LA & 1703 & 166 \\
\hline NcGOM & 8112 & 373 \\
\hline $\mathrm{TX}$ & 227 & 40 \\
\hline
\end{tabular}

(0.57/year [95\% CI: 0.52-0.61]) was lower than the values from both the Fabens VBGF model (0.62/year [95\% CI: 0.56-0.69]) and the Gompertz model (0.84/year [95\% CI: $0.77-0.92]$ ). The estimated value of $L_{\infty}$ from the GROTAG VBGF model was in the range of values reported from Virginia, Louisiana, North Carolina and the Gulf of Mexico (Richards, 1967; Thompson et al. ${ }^{9}$; Smith, 1995; Franks et al., 1999; Table 3). However, the estimate of $k$ was higher in our analysis than those values reported for Virginia, North Carolina and the Gulf of Mexico (Table 3). The closest values to those estimated in this study were the estimates of $k$ reported from Louisiana (Thompson et al. ${ }^{9}$ ). In the most recent Gulf of Mexico and South Atlantic Ocean assessments, the models used to describe length-at-age relationships were also sex aggregated (SEDAR ${ }^{1}$ ), however the estimates of $L_{\infty}$ in the SEDAR assessments were greater than the estimate in our study and the SEDAR estimates of $k$ were lower than the value estimated in our study (Table 3).

\section{Table 2}

Parameter estimates, with $95 \%$ confidence intervals, from nonlinear models fitted to information on tagging and recapture of cobia (Rachycentron canadum) in the Gulf of Mexico and South Atlantic Ocean during 1988-2014. The mean asymptotic length $\left(L_{\infty}\right)$, provided as millimeters in fork length ( $\mathrm{CI}=$ confidence interval), and the annual growth coefficient $(k)$ were estimated for 2 parameterizations of the von Bertalanffy growth function (VBGF) and a Gompertz model. The 2 parameterizations were the VBGF used in the program GROTAG and the VBGF used by Fabens (1965). The relative model support was evaluated by using Akaike's information criterion (AIC), and Akaike weight $\left(w_{\mathrm{i}}\right)$ was calculated for each model.

\begin{tabular}{lccrc}
\hline Model & $L_{\infty}(\mathrm{CI})$ & \multicolumn{1}{c}{$\Delta$ AIC } & \multicolumn{1}{c}{$w_{\mathrm{i}}$} \\
\hline GROTAG VBGF & $1172(1151-1192)$ & $0.57(0.52-0.61)$ & 0.00 & 1.00 \\
Fabens VBGF & $1189(1163-1219)$ & $0.62(0.56-0.69)$ & 119.70 & 0.00 \\
Gompertz & $1157(1135-1181)$ & $0.84(0.770 .92)$ & 153.80 & 0.00
\end{tabular}




\section{Table 3}

Estimates of von Bertalanffy growth function parameters for cobia (Rachycentron canadum) from previously published studies and this study. The 3 parameters are mean asymptotic length $\left(L_{\infty}\right)$, provided as millimeters in fork length (FL), annual growth coefficient $(k)$, and hypothetical age at length of zero $\left(t_{0}\right)$. For parameter values, standard errors of the mean are provided for some studies and the 95\% confidence intervals (CIs) are provided for this study in parentheses. The locations were Virginia (VA), Louisiana (LA), North Carolina (NC), the northeastern Gulf of Mexico (nGOM), and the Gulf of Mexico (GOM).

\begin{tabular}{|c|c|c|c|c|c|c|}
\hline Study & Location & Sex & $n$ & $L_{\infty}(\mathrm{mm} \mathrm{FL})$ & $k$ & $t_{0}($ years $)$ \\
\hline \multirow[t]{2}{*}{ Richards, 1967} & VA & M & 88 & 1210 & 0.28 & -0.06 \\
\hline & & $\mathrm{F}$ & 135 & 1640 & 0.23 & -0.08 \\
\hline \multirow[t]{2}{*}{ Thompson et al. ${ }^{9}$} & LA & M & 464 & 1132 & 0.49 & -0.49 \\
\hline & & $\mathrm{F}$ & 218 & 1294 & 0.56 & 0.11 \\
\hline \multirow[t]{2}{*}{ Smith, 1995} & $\mathrm{NC}$ & $\mathrm{M}$ & 116 & $1050(18.5)$ & $0.37(0.04)$ & $-1.08(0.29)$ \\
\hline & & $\mathrm{F}$ & 92 & $1350(38.2)$ & $0.24(0.03)$ & $-1.53(0.39)$ \\
\hline \multirow[t]{2}{*}{ Franks et al., 1999} & nGOM & M & 170 & $1171(28.1)$ & $0.43(0.05)$ & $-1.15(0.17)$ \\
\hline & & $\mathrm{F}$ & 395 & $1555(35.1)$ & $0.27(0.02)$ & $-1.25(0.09)$ \\
\hline SEDAR $^{1}$ & GOM & combined & & 1282 & 0.42 & -0.53 \\
\hline $\mathrm{SEDAR}^{1}$ & Atlantic Ocean & combined & 2485 & 1324 & 0.27 & -0.47 \\
\hline This study & GOM & combined & 926 & $1172(1151-1192)$ & $0.57(0.52-0.61)$ & NA \\
\hline
\end{tabular}

\section{Movement and seasonal distribution}

Movement among zones Seven geographic zones were defined in our study to determine the large-scale and seasonal movements of cobia (Fig. 1). Large-scale movement patterns of cobia in the Gulf of Mexico and South Atlantic Ocean were observed. Notably, a portion of the individuals tagged in the Florida Keys, Florida panhandle, Louisiana, and northcentral Gulf of Mexico zones were recaptured in the South Atlantic Ocean zone and therefore indicated that cobia migrate around Florida between the Gulf of Mexico and South Atlantic Ocean (Table 4). Individuals tagged in the Texas zone were recaptured only in the Louisiana and Texas zones and thus indicated that cobia in the western Gulf of Mexico may exhibit limited movement or could be a resident group (Table 4). However, it is important to note that a relatively low number of individuals were tagged and recaptured in the Texas zone over the entire duration of the tagging program (227 tagged, 40 recaptured, Table 1). A majority of individuals tagged in a given zone were recaptured in the same zone for all zones except the Florida panhandle zone where the majority of recaptures were distributed among the Florida panhandle, Louisiana, and northcentral Gulf of Mexico zones (Table 4). Unfortunately, because of the lack of resolution in the reported tagging and recapture locations, we could not evaluate how time-at-liberty affects individual movement between zones.

\section{Table 4}

A matrix of the number and proportion of cobia (Rachycentron canadum) ( $n=875$, time-at-liberty $\geq 30$ days) tagged and recaptured in the Gulf of Mexico and South Atlantic Ocean during 1988-2014 and the recapture percentage among the 7 geographic zones used in this study. The zones are the South Atlantic Ocean (ATL). Florida Gulf Coast (FLGC), Florida Keys (FLK), Florida panhandle (FLPH), Louisiana (LA), northcentral Gulf of Mexico (NcGOM), and Texas (TX).

\begin{tabular}{|c|c|c|c|c|c|c|c|c|c|c|c|c|c|c|c|}
\hline \multirow{2}{*}{$\begin{array}{l}\text { Zone of } \\
\text { tagging }\end{array}$} & \multicolumn{8}{|c|}{ Zone of recapture } & \multicolumn{7}{|c|}{ Recapture percentage } \\
\hline & ATL & FLGC & FLK & FLPH & LA & NcGOM & $\mathrm{TX}$ & Total & ATL & FLGC & FLK & FLPH & LA & NcGOM & $\mathrm{TX}$ \\
\hline ATL & $\mathbf{3 0}$ & 0 & 5 & 2 & 1 & 2 & 0 & 40 & 0.75 & 0 & 0.12 & 0.05 & 0.02 & 0.05 & 0 \\
\hline FLGC & 0 & 30 & 7 & 6 & 2 & 1 & 0 & 46 & 0 & 0.65 & 0.15 & 0.13 & 0.04 & 0.02 & 0 \\
\hline FLK & 6 & 9 & 63 & 18 & 4 & 7 & 1 & 108 & 0.06 & 0.08 & 0.58 & 0.17 & 0.04 & 0.06 & 0.01 \\
\hline FLPH & 30 & 9 & 24 & 73 & 61 & 63 & 16 & 276 & 0.11 & 0.03 & 0.09 & 0.26 & 0.22 & 0.23 & 0.06 \\
\hline LA & 3 & 1 & 3 & 5 & 41 & 3 & 5 & 61 & 0.05 & 0.02 & 0.05 & 0.08 & 0.67 & 0.05 & 0.08 \\
\hline NcGOM & 15 & 10 & 33 & 55 & 35 & 184 & 7 & 339 & 0.04 & 0.03 & 0.1 & 0.16 & 0.1 & 0.54 & 0.02 \\
\hline $\mathrm{TX}$ & 0 & 0 & 0 & 0 & 1 & 0 & 4 & 5 & 0 & 0 & 0 & 0 & 0.2 & 0 & 0.8 \\
\hline Total & 84 & 59 & 135 & 159 & 145 & 260 & 33 & 875 & & & & & & & \\
\hline
\end{tabular}




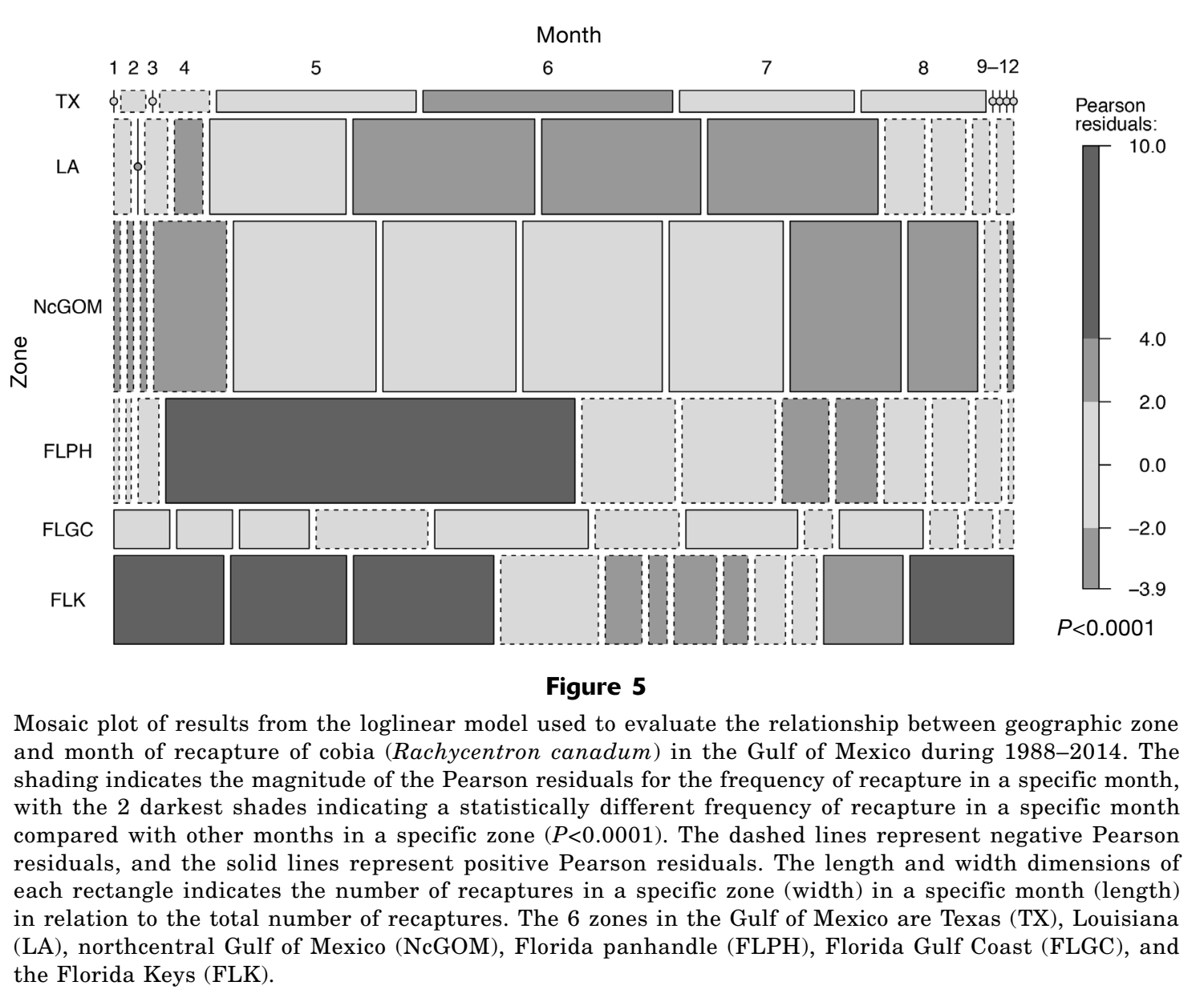

Seasonal distribution A strong seasonal trend in cobia recaptures was observed with a large portion of winter recaptures occurring in the Florida Keys zone and summer recaptures occurring in the northcentral Gulf of Mexico and Louisiana zones. The largest number of recaptures in the Louisiana and northcentral Gulf of Mexico zones occurred from May through August. The saturated loglinear model was not significant $\left(\chi^{2}: 0.0\right.$, $P=1$ ) and upon removal of the interaction term, the model became significant $\left(\chi^{2}: 465.6, P<0.001\right)$, indicating there was a significant association between recapture zone and month of recapture. Specifically, based on the Pearson residuals and resulting mosaic plot, the frequency of cobia recaptures in the Florida Keys zone was significantly lower from May to August and significantly greater from November to March than for other months (Fig. 5). Additionally, the frequency of cobia recaptures in the northcentral Gulf of Mexico zone was significantly lower from December to April and significantly greater in September and October than for other months (Fig. 5). In the Louisiana zone, the frequency of cobia recaptures was significantly greater from June to August than in other months, in the Texas zone, the frequency of cobia recaptures was significantly greater in June, and in the Florida panhandle zone the frequency of recaptures was significantly greater in April than in other months and lower in July and August (Fig. 5).

\section{Mortality}

An annual recovery matrix containing 27 years of tagrecovery data was used to determine estimates of $S$ and $f$ parameters in the software program MARK. Only individuals that were not rereleased (i.e., were harvested) and whose dates of tagging and recapture were reported were used in the analysis $(n=903)$. Four candidate models were evaluated, each having a unique combination of time-dependent and time-independent survivorship and tag-recovery (Table 5). Global model fit, for the $S(t)$ and $f(t)$ parameters, was evaluated by using $\hat{c}$. The estimated value of $\hat{c}$ determined from the goodness-of-fit simulation was 2.02 and indicated some overdispersion. The best supported candidate model included $S($.) and $f(t)$ parameters (Table 5). The estimate of annual survival from the most supported model was 0.56 (95\% CI: $0.53-0.58$ ). This value is equivalent to an annual $Z$ of $0.59 /$ year (95\% CI: $0.55-0.63$ ). The an- 


\section{Table 5}

Candidate models evaluated for estimation of survivorship $(S)$ and probability of tag recovery $(f)$ with data from tagging and recapture of cobia (Rachycentron canadum) in the Gulf of Mexico and South Atlantic Ocean during 1988-2014. Time-invariant parameters are represented by (.) and time-variant parameters are represented by (t). The models were evaluated by using Akaike's information criterion (AIC), and Akaike weight $\left(w_{\mathrm{i}}\right)$ was calculated for each model.

\begin{tabular}{lcccc}
\hline Model & AICc & $\Delta$ AICc & $\begin{array}{c}\text { AICc } \\
\text { weight }\end{array}$ & $\begin{array}{c}\text { Model } \\
\text { likelihood }\end{array}$ \\
\hline$S() f.(\mathrm{t})$ & 10081.5 & 0.00 & 0.79 & 1.00 \\
$S() f.()$. & 10084.2 & 2.72 & 0.20 & 0.26 \\
$S(\mathrm{t}) f(\mathrm{t})$ & 10091.3 & 9.82 & 0.01 & 0.01 \\
$S(\mathrm{t}) f()$. & 10109.7 & 28.19 & 0.00 & 0.00 \\
& & & & \\
\hline
\end{tabular}

nual tag-recovery rate ranged from 0.013 to 0.041 and averaged 0.023 (Fig. 6). Peaks in tag-recovery rates occurred in 1993 and from 2006 to 2007; however, the $f$ parameter remained relatively constant throughout the duration of the tagging program (Fig. 6).

\section{Discussion}

In the most recent Gulf of Mexico cobia stock assessment $\left(\mathrm{SEDAR}^{1}\right)$, several research needs were identified that, if resolved, would help enable reviewers to evaluate the appropriateness of an assessment model and allow the determination of stock status to be made. The information provided in this study fills information gaps that exist for cobia in the Gulf of Mexico and South Atlantic Ocean that will aid in future assessment efforts and allow for an accurate determination of stock status. The information includes an alternative approach to modeling the length-at-age relationship, a description of the annual $Z$ and elucidation of the annual movement, and the distribution patterns of individuals.

A primary objective of our research was to provide alternative length-atage parameter estimates and compare them with estimates available in the published literature. Of the models we evaluated, the GROTAG VBGF model resulted in the best option for fitting growth increment information from tag-recapture studies because it explicitly addresses variability in individual growth, effectively handles the presence of outliers, and is able to accurately evaluate mean values of $L_{\infty}$-a failing of other algorithms with tag and recapture information (e.g., Fabens, 1965). Our mean estimate of $L_{\infty}$ derived from the length-at-age analysis with the GROTAG VBGF model is lower than estimates reported in other studies of individual growth dynamics with the use of otoliths. This result could be due to the sex-aggregated nature of the tagging data that were available (our estimate was often higher than male-specific estimates and lower than female-specific estimates, Table 3). The lack of sex-specific information is a confounding feature of cooperative tagging programs (Dippold et al., 2016) and likely has an effect on the estimated length-at-age parameters. Another possible explanation for the lower $L_{\infty}$ reported here is that anglers typically keep cobia of legal length $(\geq 84 \mathrm{~cm}$ or 33 in) and tagged individuals were generally smaller or close to the minimum length limit, both of which may bias our length-at-age parameter estimates. We also found that the mean $k$ in this study was greater than that of many other published estimates (Table 3 ). Because the VBGF parameters are strongly and negatively correlated, the higher $k$ estimate may be in part caused by the lower estimate of $L_{\infty}$. Despite the sexual dimorphism in length-at-age between males and females, both the SEDAR assessments of cobia in the Gulf of Mexico and Atlantic Ocean used a sex-combined 3-parameter VBGF to describe the length-at-age relationship. Therefore, although in the tagging program data that we evaluated, sex was not recorded, and the lack of sex determination is a disadvantage of coop-

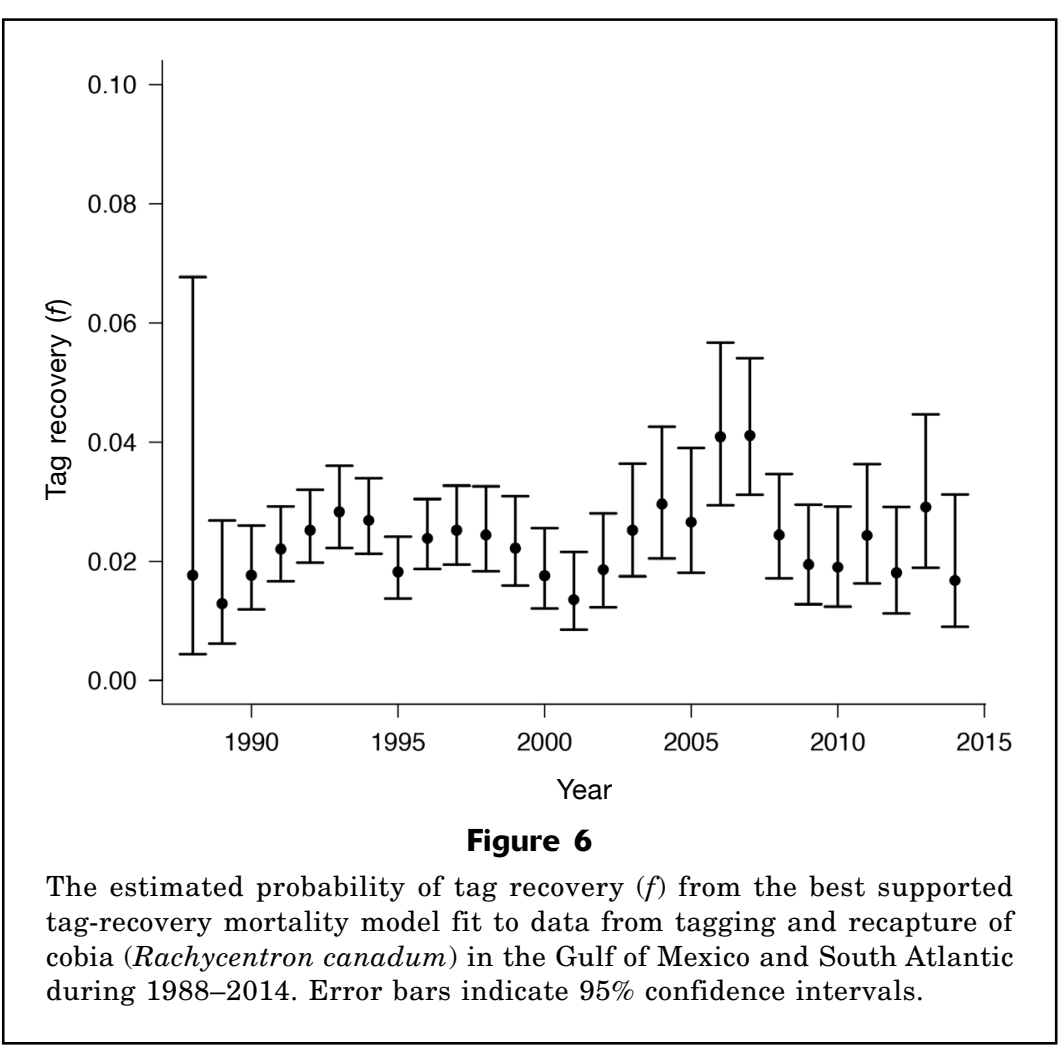


erative tagging programs, our estimates are still a relevant method of corroboration given that sex-combined length-at-age models are used in current assessment models. However, in the future, we recommend that sex of recaptured individuals be reported if available. This information could be collected at fishing tournaments where scientists are often on site gathering biological information, or incentives could be offered to bring carcasses to scientists for sex identification.

As with the description of individual growth dynamics, we provide an independent estimate of $Z$ that can be used to corroborate mortality values estimated by using an age-structured stock assessment model. In most stock assessment frameworks, natural and fishing mortality rates are difficult to estimate and are often obtained by theoretical estimates (Then et al., 2015). Tag-recovery models do not require the use of a specific natural mortality function to estimate $Z$, and thus avoid some potential biases in describing the natural mortality component of $Z$. In this study, we estimated annual $Z$ by using tag-recovery models (0.59/year [95\% CI: $0.55-0.63])$. In the 2013 stock assessment of cobia in the Gulf of Mexico, the current estimated annual total mortality (the sum of the geometric mean fishing mortality and natural mortality) was $0.62 /$ year. During the period included in the assessment, fishing mortality varied annually but has remained relatively stable, especially in the most recent years of the assessment. Our estimate of $Z$ is similar to those values estimated in the stock assessment model. We included recaptures from both the Gulf of Mexico and a limited number from the South Atlantic Ocean in our analysis (to account for individuals tagged in Gulf of Mexico and harvest in South Atlantic Ocean) and recognize that our estimate is by necessity stock-aggregated.

Clarification of the stock boundary along the Atlantic coast of Florida was considered a research need of high importance by assessment scientists (SEDAR ${ }^{1}$ ), and cooperative research efforts can contribute to this effort (Lucy and Davy, 2000). This study confirms the presence of large scale movements of individual cobia within the Gulf of Mexico and into the South Atlantic Ocean. The scale of our work, in terms of both the number of individuals tagged and the spatial coverage, is greater than that of previous studies and strengthens the descriptions of cobia movement. Previously, Burns and Neidig 6 tagged 171 cobia from 1990 to 1992 , recaptured 10 individuals and suggested both seasonal northern and southern movements and seasonal onshore-offshore movements. Orbesen ${ }^{8}$ synthesized cooperative tagging information collected from the NOAA Southeast Fisheries Science Center, information that included 1510 tagged cobia and 148 recaptures over 58 years. Using that synthesized recapture information and the 6 defined geographic zones (as opposed to the 7 zones defined in our study), Orbesen ${ }^{8}$ observed mixing among all 6 zones, and that more mixing occurred between the Keys and the Gulf zones than between any other 2 zones. For the South Carolina Marine Game Fish Tagging Program, 1066 cobia were tagged be- tween 1986 and 2009 and 201 individuals were recaptured (Wiggers ${ }^{7}$ ). On the basis of the reported tagging and recapture locations, most fish showed site fidelity, although some mixing between the Gulf of Mexico and South Atlantic Ocean was observed. Other studies have also reported mixing between the Gulf of Mexico and South Atlantic Ocean on the basis of a few recaptured individuals (Shaffer and Nakamura, 1989). Most of these tagging studies had a small number of recaptured individuals or were conducted for a relatively short time period (or were a combination of both). Because of the observed long-distance movements and the current problems with identification of the stock boundary between the Gulf of Mexico and South Atlantic Ocean stocks, the relatively greater number of tagged and recaptured individuals used in this study and the duration of the tagging program allow stronger inferences of seasonal and long-distance movement patterns of cobia in the Gulf of Mexico and South Atlantic Ocean.

The results of our work indicate that there is an evident seasonal distribution pattern: individuals are more frequently recaptured in the Florida Keys during the winter and in the northern Gulf of Mexico during the summer. Currently, the South Atlantic Ocean and Gulf of Mexico stocks are divided at the Florida-Georgia state line $\left(\mathrm{SEDAR}^{1}\right)$. The boundary is determined on the basis of ease of management; however, there is little evidence from genetic or tagging work to confirm the validity of this designation $\left(\mathrm{SEDAR}^{1}\right)$. Some genetic evidence indicates homogeny among offshore cobia along the Atlantic coast and some genetic distinction among inshore aggregations; however, no similar genetic information on population structure and partitioning exists for cobia in the Gulf of Mexico (Darden et al., 2014). We find that of the individuals tagged in the Gulf of Mexico zones, no more than $11 \%$ of recaptures of individuals tagged in a given Gulf of Mexico zone occurred in the South Atlantic Ocean. Additionally, of the individuals tagged in the Atlantic Ocean and subsequently recaptured, only $14 \%$ were recaptured in the Florida Keys, and recapture rates in the other Gulf of Mexico zones ranged from 0 to $5 \%$. These results suggest that the Florida Keys may be a mixing zone and that the current stock boundary at the Florida Georgia state line may be inappropriate. However, we did not incorporate differences in fishing and sampling effort into our modeling approaches and we note that seasonal differences in fishing effort between zones may bias our descriptions of movement and seasonal recapture patterns. Additionally, because of the scope of the cooperative tagging program, we were limited to providing descriptions of movement and distribution to the Gulf of Mexico and South Atlantic Ocean.

The results of our research suggest a seasonal pattern of distribution of cobia in the Gulf of Mexico. Specifically, the results of the loglinear analysis presented here indicate that the Florida Keys may be a wintering ground for cobia and that individuals may exhibit northward movement toward the Florida panhandle 
in the spring, followed by summer residence in the northern Gulf of Mexico and Louisiana. These patterns are similar to patterns reported in other cooperative tagging studies (Shaffer and Nakamura, 1989; Burns and Neidig6). However, to our knowledge, this is the first study to quantify and statistically test potential trends in seasonal distribution of cobia recaptures. The observed seasonal movement patterns may have implications for cobia management in the Gulf of Mexico. Inappropriate designation of the stock boundary could affect the spatial extent of the indices of abundance used in the assessment, as well as on the spatial allocation of harvest patterns on the Atlantic coast of Florida. However, we do note that differences in seasonal fishing effort may be in part responsible for observed differences in recapture distribution.

\section{Acknowledgments}

We thank the numerous anglers whose tremendous tagging efforts made this study possible. We also thank D. Gibson for management of the database. Funding for the Sport Fish Tag and Release Program was provided by the U.S. Fish and Wildlife Service's Sport Fish Restoration Program and the Mississippi Department of Marine Resources. Funding for this study was provided by the Mississippi Department of Marine Resources Tidelands Trust Fund Program "Mississippi Stock Assessment Panel" grant awarded to J. Hendon and $\mathrm{R}$ Leaf.

\section{Literature cited}

Brownie, C., D. R. Anderson, K. P. Burnham, and D. S. Robson. 1985. Statistical inference from band recovery data: a handbook, $2^{\text {nd }}$ ed. U.S. Fish Wildl. Serv. Resour. Publ. $156,305 \mathrm{p}$.

Burnham, K. P., and D. R. Anderson.

2002. Model selection and multimodel inference: a practical information-theoretic approach, 2nd ed., $266 \mathrm{p}$. Springer-Verlag, New York.

Campana, S. E.

2001. Accuracy, precision and quality control in age determination, including a review of the use and abuse of age validation methods. J. Fish Biol. 59:197-242. Article

Darden, T. L., M. J. Walker, K. Brenkert, J. R. Yost, and M.

R. Denson.

2014. Population genetics of Cobia (Rachycentron canadum): implications for fishery management along the coast of the southeastern United States. Fish. Bull. 112:24-35. Article

Dippold, D. A., R. T. Leaf, J. R. Hendon, and J. S. Franks. 2016. Estimation of the length-at-age relationship of Mississippi's Spotted Seatrout. Trans. Am. Fish. Soc. 142:295-304. Article

Fabens, A. J.

1965. Properties and fitting of the von Bertalanffy growth curve. Growth 29:265-289.
Francis, R. I. C. C.

1988. Maximum likelihood estimation of growth and growth variability from tagging data. N. Z. J. Mar. Freshw. Res. 22:43-51. Article

Franks, J. S., J. R. Warren, and M. V. Buchanan.

1999. Age and growth of cobia, Rachycentron canadum, from the northeastern Gulf of Mexico. Fish. Bull. 97:459-471.

Hendon, J. R., J. R. Warren, J. S. Franks, and M. V. Buchanan. 2002. Movements of spotted seatrout (Cynoscion nebulosus) in Mississippi coastal waters based on tag-recapture. Gulf Mex. Sci. 20:91-97.

Hussey, N. E., I. D. McCarthy, S. F. J. Dudley, and B. Q. Mann.

2009. Nursery grounds, movement patterns and growth rates of dusky sharks, Carcharhinus obscurus: a longterm tag and release study in South African waters. Mar. Freshw. Res. 60:571-583. Article

Jones, C. D., and E. D. Prince.

1998. The cooperative tagging center mark-recapture database for Istiophoridae (1954-1995), with an analysis of the west Atlantic ICCAT billfish tagging program. Collect. Vol. Sci. Pap. ICCAT 47:311-322.

Katsanevakis, S.

2006. Modelling fish growth: model selection, multi-model inference and model selection uncertainty. Fish. Res. 81:229-235. Article

Kerns, J. A., M. S. Allen, J. R. Dotson, and J. E. Hightower. 2015. Estimating regional fishing mortality for freshwater systems: a Florida largemouth bass example. North Am. J. Fish. Manage. 35:681-689. Article

Kneebone, J., J. Chisholm, and G. Skomal.

2014. Movement patterns of juvenile sand tigers (Carcharias taurus) along the east coast of the USA. Mar. Biol. 161(5):1149-1163. Article

Knoke, D., and P. J Burke.

1980. Log-linear models, vol. 20, 80 p. Sage Publications Inc. Thousand Oaks, CA.

Kohler, N. E., J. G. Casey, and P. A. Turner.

1998. NMFS cooperative shark tagging program, 196293: an atlas of shark tag and recapture data. Mar. Fish. Rev. 60(2):1-87.

Lucy, J., and K. Davy.

2000. Benefits of angler-assisted tag and release programs. Fisheries 25(4):18-23. Article

Natanson, L. J., J. G. Casey, N. E. Kohler, and T. Colket IV. 1999. Growth of the tiger shark, Galeocerdo cuvier, in the western North Atlantic based on tag returns and length frequencies; and a note on the effects of tagging. Fish. Bull. 97:944-953.

Ortiz, M., E. D. Prince, J. E. Serafy, D. B. Holts, K. B. Davy, J. G. Pepperell, M. B. Lowry, and J. C. Holdsworth.

2003. Global overview of the major constituent-based billfish tagging programs and their results since 1954. Mar. Freshw. Res. 54:489-507. Article

Pierce, L. L., B. D. S. Graeb, D. W. Willis, and J. S. Sorensen. 2015. Evaluating effects of exploitation on annual apparent mortality rates of paddlefish using mark-recapture data. Trans. Am. Fish. Soc. 144:337-344. Article

Pine, W. E., K. H. Pollock, J. E. Hightower, T. J. Kwak, and J. A. Rice.

2003. A review of tagging methods for estimating fish population size and components of mortality. Fisheries 28(10):10-23. Article 
Queiroz, N., F. P. Lima, A. Maia, P. A. Ribeiro, J. P. Correia, and A. M. Santos.

2005. Movement of blue shark, Prionace glauca, in the north-east Atlantic based on mark-recapture data. J. Mar. Biol. Assoc. U. K. 85:1107-1112. Article

$\mathrm{R}$ Core Team.

2016. R: a language and environment for statistical computing. R Foundation for Statistical Computing, Vienna, Austria. [Available from Article, accessed May 2016.]

Richards, C. E.

1967. Age, growth and fecundity of the cobia, Rachycentron canadum, from Chesapeake Bay and adjacent mid-Atlantic waters. Trans. Am. Fish. Soc. 96:343-350. Article

Shaffer, R. V., and E. L. Nakamura.

1989. Synopsis of biological data on the cobia Rachycentron canadum (Pisces: Rachycentridae). NOAA Tech. Rep. NMFS 82, 21 p.

Simpfendorfer, C. A.

2000. Growth rates of juvenile dusky sharks, Carcharhinus obscurus (Lesueur, 1818), from southwestern Australia estimated from tag-recapture data. Fish. Bull. 98:811-822.

Smith, J.

1995. Life history of cobia, Rachycentron canadum (Osteichthyes: Rachycentridae), in North Carolina waters. Brimleyana 23:1-23.
Then, A. Y., J. M. Hoenig, N. G. Hall, and D. A. Hewitt.

2015. Evaluating the predictive performance of empirical estimators of natural mortality rate using information on over 200 fish species. ICES J. Mar. Sci. 72:82-92. Article

Troynikov, V. S., R. W. Day, and A. M. Leorke.

1998. Estimation of seasonal growth parameters using a stochastic Gompertz model for tagging data. J. Shellfish Res. 17:833-838.

Vandergoot, C. S., and T. O. Brenden.

2014. Spatially varying population demographics and fishery characteristics of Lake Erie walleyes inferred from a long-term tag recovery study. Trans. Am. Fish. Soc. 143:188-204. Article

White, G. C., and K. P. Burnham.

1999. Program MARK: survival estimation from populations of marked animals. Bird Study 46:S120-S138. Article

Williams, E. H.

2001. Assessment of cobia, Rachycentron canadum, in the waters of the U.S. Gulf of Mexico. NOAA Tech. Memo. NMFS-SEFSC-469, $55 \mathrm{p}$.

Wood, A. D., and S. X. Cadrin.

2013. Mortality and movement of yellowtail flounder $(\mathrm{Li}$ manda ferruginea) tagged off New England. Fish. Bull. 111:279-287. Article 